\title{
STIGMA DAN DISKRIMINASI TERHADAP ODHA (STUDI PADA TENAGA KESEHATAN DI PUSKESMAS TANAH PASIR ACEH UTARA)
}

\author{
Rizka Sofia* \\ Bagian Parasitologi Fakultas KedokteranUniversitas Malikussaleh \\ Lhokseumawe 24311, Indonesia \\ *Corresponding author : drrizkasofia@gmail.com
}

\begin{abstract}
Abstrak
Penghapusan stigma dan diskriminasi terhadap ODHA merupakanbagian terpenting dalam Gerakan Nasional HIV/AIDS (GNHA). Melalui penghapusan stigma dan diskriminasi, proses preventif dan kuratif terhadap kasus HIV/AIDS menjadi lebih optimal. Oleh karena itu, penelitian ini bertujuan untuk menilai tingkat stigma dan diskriminasi pada tenaga kesehatan terkait penyakit HIV/AIDS di Puskesmas Tanah Pasir serta menganalisis faktor-faktor yang mempengaruhinya. Penelitian ini merupakan penelitian observasional dengan rancangan potong lintang (cross sectional study). Populasi penelitian ini adalah seluruh tenaga kesehatan di Puskesmas Tanah Pasir dan metode pengambilan sampel pada penelitian ini adalah dengan metode total sampling, dengan jumlah sampel dalam penelitian ini berjumlah 50 responden. Metode analisis data yang digunakan adalah analisis univariat dan analisis bivariat menggunakan Uji Chi Square. Hubungan tingkat pengetahuan HIV/AIDS dengan stigma ODHA diperoleh $p$-value $=0,03$. Sementara itu hasil pengujian hubungan tingkat pengetahuan HIV / AIDS dengan diskriminasi ODHA juga diperoleh nilai $p$-value $=$ 0,05 . Hubungan ketakutan irasional terhadap transmisi HIV/AIDS dengan stigma tenaga kesehatan di Puskesmas Tanah Pasir terhadap ODHA diperoleh nilai $p$ value $=0,02$. Sementara itu hubungan ketakutan irasional terhadap transmisi HIV/AIDS dengan diskriminasi tenaga kesehatan di Puskesmas Tanah Pasir terhadap ODHA diperoleh nilai $p$-value $=0,04$. Penelitian ini menunjukkan bahwa tingkat pengetahuan tentang HIV/AIDS dan tingkat ketakutan irasional tentang transmisi HIV mempunyai hubungan dengan stigma dan diskriminasi tenaga kesehatan Puskesmas Tanah Pasir terhadap ODHA.
\end{abstract}

Kata kunci: Diskriminasi; HIV/AIDS; Stigma 


\title{
STIGMA AND DISCRIMINATION AGAINST AIDS (STUDIES IN HEALTH WORKERS IN THE TANAH PASIR HEALTH CENTER OF NORTH ACEH)
}

\begin{abstract}
Elimination of negative perception and discrimination against people living with HIV-AIDS (PLWHA) is one of the most important parts of the National Movement of HIV/AIDS (GNHA). Through the elimination of negative perception and discrimination, the process of preventive and curative against HIV/AIDS cases become more optimal in order to succeed GNHA. This study aims to assess the level of negative perception and discrimination on health personnel-related HIV/AIDS at the health center of Tanah Pasir and analyzes the factors that influence the level of negative perception and discrimination on health personnelrelated HIV/AIDS. This study was an observational study with cross sectional design. The study population was all health workers in health centers of Tanah Pasir. This study was use the total sampling method and the number of samples were 50 respondents. Data were analyze by Chi-Square test. Correlation between knowledge of HIV/AIDS negative perception of PLWHA was obtained p-value of 0.03. Meanwhile, the correlation between knowledge of HIV/AIDS and discrimination of PLWHA also obtained p-value of 0.05. Relations irrational fear of transmission of HIV/AIDS and negative perception of health workers was obtained nilai p-value of 0.02 . The relations between irrational fear of transmission of HIV/AIDS and discrimination of health workers in health centers for PLHA obtained p-value of 0.04 . This study concluded that the level of knowledge of HIV/AIDS and the level of irrational fears about HIV transmission has a relationship with the health personnel negative perception and discrimination against people living with HIV Health Center of Tanah Pasir.
\end{abstract}

Key words:Discrimination; HIV/AIDS; Negative Perception. 


\section{Pendahuluan}

Estimasi Kementerian Kesehatan RI pada tahun 2009 menyebutkan bahwa orang yang terinfeksi HIV di Indonesia mencapai angka 186.257. Sedangkan jumlah kasus AIDS yang tercatat dalam laporan kasus di Kementerian Kesehatan hingga Desember 2010 sebanyak 24.131 orang. Dalam konteks Aceh, data HIV dan AIDS sulit diperoleh secara akurat karena kasus HIV dan AIDS merupakan fenomena gunung es, hanya yang di permukaannya saja yang kelihatan, sedangkan di bawahnya yang lebih besar tidak kelihatan. Salah satu penyebab fenomena ini adalah masih adanya stigma negatif dan diskriminasi terhadap orang dengan HIV/ AIDS (ODHA). ${ }^{19}$

Stigma dan diskriminasi terhadap ODHA menyebabkan sebuah hambatan utama bagi ODHA yang ingin mengakses pengobatan, perawatan, pendidikan, dan informasi untuk mencegah penularan HIV. ${ }^{37}$ Penghapusan stigma dan diskriminasi terhadap ODHA merupakan salah satu bagian terpenting dalam Gerakan Nasional HIV/AIDS (GNHA). Dengan penghapusan stigma dan diskriminasi, proses preventif dan kuratif terhadap kasus HIV/AIDS menjadi lebih optimal guna menyukseskan GNHA. Oleh karena itu, penelitian ini bertujuan untuk menilai tingkat stigma dan diskriminasi pada tenaga kesehatan terkait penyakit HIV/AIDS di Puskesmas Tanah Pasir serta menganalisis faktor-faktor yang mempengaruhinya.

\section{Metode}

Penelitian ini merupakan penelitian observasional dengan rancangan potong lintang (cross sectional study), yaitu suatu rancangan penelitian yang mempelajari dinamika korelasi antara variabel independen dengan variabel dependen dengan melakukan pengukuran sesaat. ${ }^{7}$ Populasi penelitian ini adalah seluruh tenaga kesehatan di Puskesmas Tanah Pasir yang berjumlah 50 orang. Metode yang digunakan untuk pengambilan sampel adalah metode total sampling. Jadi jumlah sampel dalam penelitian ini berjumlah 50 responden. Metode analsis data yang digunakan dalampenelitian ini yaitu sebagai berikut:

1. Analisis Univariat

Analisis univariat digunakan untuk mengetahui gambaran distribusi frekuensi responden,tingkat pengetahuan tentang HIV/AIDS, ketakutan yang irasional terhadap transmisi HIV/AIDS, tingkat stigmadan diskriminasi ODHA oleh tenaga kesehatan.

2. Analisis Bivariat

Analisis bivariat digunakan untuk mengetahui hubungan tingkat pengetahuan tentang HIV/AIDS dengan stigma dan diskriminasi tenaga kesehatan, serta untuk mengetahui hubungan ketakutan irrasional terhadap transmisi HIV/AIDS dengan stigma dan diskriminasi ODHA oleh tenaga kesehatan dengan menggunakan UjiChi Square.

\section{Hasil Penelitian}

\section{Analisis Univariat}

\section{Karakteristik Responden}

Karakteristik tenaga kesehatan yang menjadi responden di Puskesmas Tanah Pasir dapat digambarkan seperti tabel 1 berikut ini:

Tabel 1. Distribusi frekuensi responden berdasarkan usia, jenis kelamin, tingkat pendidikan, dan status perkawinan.

\begin{tabular}{lcc}
\hline Kategori & $\begin{array}{c}\text { Frekuensi } \\
(\mathbf{F})\end{array}$ & $\begin{array}{c}\text { Persentase } \\
(\mathbf{\%})\end{array}$ \\
\hline Usia: & & \\
$24-37$ & 23 & 46,0 \\
$38-51$ & 27 & 54,0 \\
\hline Jumlah & 50 & 100,0 \\
\hline
\end{tabular}




\begin{tabular}{lcc}
\hline Jenis Kelamin: & 21 & 42,0 \\
Laki-laki & 29 & 58,0 \\
Perempuan & 50 & 100,0 \\
\hline Jumlah & 22 & 44,0 \\
\hline Tingkat Pendidikan: & 28 & 56,0 \\
$\begin{array}{l}\text { Diploma III } \\
\text { Sarjana }\end{array}$ & 50 & 100,0 \\
\hline Jumlah & 16 & 32,0 \\
\hline Status Perkawinan: & 34 & 68,0 \\
Belum kawin & 50 & 100,0 \\
Kawin &
\end{tabular}

Sumber: data diolah (2015)

Dari tabel 1 di atas dapat dilihat bahwa jumlah responden berdasarkan kelompok usia 24-37 tahun sebanyak 23 orang (46\%) dan usia 38-51 tahun sebanyak 27 orang (54\%).Berdasarkan hasil tersebut dapat disimpulkan bahwa tenaga kesehatan yang dominan di Puskesmas Tanah Pasir yaitu tenaga kesehatan yang berumur 38-51 tahun.

Jumlah responden berdasarkan jenis kelamin yaitu laki-laki sebanyak 21 orang $(42 \%)$ dan perempuan 29 orang (58\%).Hal ini menunjukkan bahwa tenaga kesehatan di Puskesmas Tanah Pasir lebih banyak berjenis kelamin perempuan.

Berdasarkan tingkat pendidikan terakhir, responden yang mempunyai latar belakang pendidikan Diploma III sebanyak 22 orang $(44 \%)$ dan sarjana sebanyak 28 orang (56\%).Hal ini menunjukkan bahwa sebagian besar tenaga kesehatan di Puskesmas Tanah Pasir berlatar belakang pendidikan S1.

Berdasarkan status perkawinan, jumlah responden dengan status sudah kawin sebanyak 34 orang $(68 \%)$ sedangkan yang belum kawin sebanyak 16 orang $(32 \%)$.Hal ini menunjukkan bahwa sebagian besar tenaga kesehatan di Puskesmas Tanah Pasir sudah kawin.
Stigma Tenaga Kesehatan terhadap ODHA.

Gambaran sikap stigmatisasi tenaga kesehatan di Puskesmas Tanah Pasir terhadap ODHA yaitu seperti pada tabel 2 berikut ini:

Tabel 2. Stigma Tenaga Kesehatan Puskesmas Tanah Pasir terhadap ODHA

\begin{tabular}{c|c|c}
\hline Tingkat Stigma & $\begin{array}{c}\text { Frekuensi } \\
\text { (F) }\end{array}$ & $\begin{array}{c}\text { Persentase } \\
\mathbf{( \% )}\end{array}$ \\
\hline Tinggi & 33 & 66,0 \\
Rendah & 17 & 34,0 \\
\hline Jumlah & 50 & 100,0 \\
\hline
\end{tabular}

Sumber: data diolah (2015)

Berdasarkan data pada tabel 3.2 di atas, tenaga kesehatan di Puskesmas Tanah Pasir yang mempunyai tingkat stigma yang tinggi terhadap ODHA sebanyak 33 orang (66\%).Sedangkan tenaga kesehatan yang mempunyai stigma rendah terhadap ODHA lebih rendah yaitu sebanyak 27 orang (54\%).Hal ini menunjukkan bahwa stigma tenaga kesehatan di Puskesmas Tanah pasir terhadap ODHA tinggi.

\subsubsection{Diskriminasi Tenaga Kesehatan terhadap ODHA}

Gambaran sikap diskriminasi tenaga kesehatan di Puskesmas Tanah Pasir terhadap ODHA yaitu seperti pada tabel 3.3 berikut ini:

Tabel 3.3 Stigma Tenaga Kesehatan Puskesmas Tanah Pasir terhadap ODHA

\begin{tabular}{ccc}
\hline Tingkat Stigma & $\begin{array}{c}\text { Frekuensi } \\
(\mathbf{F})\end{array}$ & $\begin{array}{c}\text { Persentase } \\
\mathbf{( \% )}\end{array}$ \\
\hline Tinggi & 35 & 70,0 \\
Rendah & 15 & 30,0 \\
\hline Jumlah & 50 & 100,0
\end{tabular}

Sumber: data diolah (2015)

Berdasarkan data pada tabel 3.3 di atas, tenaga kesehatan di Puskesmas Tanah Pasir yang mempunyai tingkat diskriminasi yang tinggi terhadap ODHA sebanyak 35 orang $(70 \%)$, sedangkan tenaga kesehatan yang 
mempunyai stigma rendah terhadap ODHA lebih rendah yaitu sebanyak 25 orang (30\%). Hal ini menunjukkan bahwa diskriminasi tenaga kesehatan di Puskesmas Tanah pasir terhadap ODHA tinggi.

\subsubsection{Tingkat Pengetahuan Tenaga Kesehatan tentang HIV/AIDS}

Gambaran tingkat pengetahuan tenaga kesehatan di Puskesmas Tanah Pasir tentang HIV dan AIDS yaitu seperti pada tabel 3.4 berikut ini:

Tabel 3.4 Gambaran Tingkat Pengetahuan Tenaga Kesehatan Puskesmas Tanah Pasir tentang HIV dan AIDS

\begin{tabular}{ccc}
\hline Tingkat Pengetahuan & $\begin{array}{c}\text { Frekuensi } \\
\text { (F) }\end{array}$ & $\begin{array}{c}\text { Persentase } \\
\mathbf{( \% )}\end{array}$ \\
\hline Tinggi & 14 & 28,0 \\
Rendah & 36 & 72,0 \\
\hline Jumlah & 50 & 100,0
\end{tabular}

Sumber: data diolah (2015)

Berdasarkan tabel 3.4 di atas, sebagian besar tenaga kesehatan di Puskesmas mempunyai tingkat pengetahuan yang rendah terhadap HIV dan AIDS. Hal ini ditunjukkan bahwa jumlah tenaga kesehatan di Puskesmas Tanah Pasir yang mempunyai tingkat pengetahuan yang tinggi tentang HIV dan AIDS berjumlah 14 orang $(28 \%)$, sedangkan yang mempunyai tingkat pengetahuan yang rendah tentang HIV dan AIDS berjumlah 36 orang (72\%).

\subsubsection{Tingkat Ketakutan yang Irasional terhadap Transmisi HIV}

Gambaran tenaga kesehatan di Puskesmas Tanah pasir yang mengalami ketakutan irasional terhadap transmisi HIV seperti pada tabel 3.5 berikut ini:

Tabel 3.5 Gambaran Frekuensi Tingkat Ketakutan yang Irasional terhadap Transmisi HIV dan AIDS.

\begin{tabular}{ccc}
\hline Tingkat Ketakutan & $\begin{array}{c}\text { Frekuensi } \\
\text { (F) }\end{array}$ & $\begin{array}{c}\text { Persentase } \\
(\mathbf{0})\end{array}$ \\
\hline Tinggi & 27 & 54,0 \\
Rendah & 23 & 46,0 \\
\hline Jumlah & 50 & 100,0
\end{tabular}

Sumber: data diolah (2015)

Berdasarkan tabel 3.5 di atas, tenaga kesehatan di Puskesmas Tanah Pasir yang tingkat ketakutan yang irasional terhadap transmisi HIV tinggi sebanyak 27 orang (54\%), sedangkan yang tingkat ketakutan irasional terhadap transmisi HIV rendah sebanyak 23 orang (46\%).

\subsection{Analisis bivariat}

\subsubsection{Hubungan Tingkat Pengetahuan HIV/AIDS dengan Stigma Tenaga Kesehatan terhadap ODHA}

Hubungan tingkat pengetahuan HIV/AIDS dengan stigma tenaga kesehatan terhadap ODHA ditunjukkan seperti pada tabel 3.6 berikut ini:

Tabel 3.6 Hubungan Tingkat PengetahuanHIV/AIDS dengan Stigma TenagaKesehatan terhadap ODHA

\begin{tabular}{|c|c|c|c|c|c|c|c|}
\hline \multirow{3}{*}{$\begin{array}{c}\text { Tingkat Pengetahuan } \\
\text { HIV/AIDS }\end{array}$} & \multicolumn{4}{|c|}{ Stigma } & \multirow{2}{*}{\multicolumn{2}{|c|}{ Jumlah }} & \multirow{3}{*}{ P value } \\
\hline & \multicolumn{2}{|c|}{ Tinggi } & \multicolumn{2}{|c|}{ Rendah } & & & \\
\hline & $\mathbf{F}$ & $\%$ & $\mathbf{F}$ & $\%$ & $\mathbf{N}$ & $\%$ & \\
\hline Tinggi & 9 & 64,2 & 5 & 38 & 14 & 100 & 0,03 \\
\hline Rendah & 24 & 66,6 & 12 & 33,4 & 36 & 100 & \\
\hline Jumlah & & & & & 50 & 100 & \\
\hline
\end{tabular}

Sumber: data diolah (2015) 
Hasil uji statistik menunjukkan ada hubungan antara tingkat pengetahuan HIV/AIDS dengan stigma tenaga kesehatan di Puskesmas Tanah Pasir terhadap ODHA. Hal ini dibuktikan dengan nilai $p$ valuesebesar 0,03 yang lebih kecil dari 0,05 .

Tabel 3.7Hubungan Tingkat Pengetahuan HIV/AIDS dengan Diskriminasi Tenaga Kesehatan terhadap ODHA

\begin{tabular}{|c|c|c|c|c|c|c|c|}
\hline \multirow{3}{*}{$\begin{array}{c}\text { Tingkat Pengetahuan } \\
\text { HIV/AIDS }\end{array}$} & \multicolumn{4}{|c|}{ Diskriminasi } & \multirow{2}{*}{\multicolumn{2}{|c|}{ Jumlah }} & \multirow{3}{*}{$p$ value } \\
\hline & \multicolumn{2}{|c|}{ Tinggi } & \multicolumn{2}{|c|}{ Rendah } & & & \\
\hline & $\mathbf{F}$ & $\%$ & $\mathbf{F}$ & $\%$ & $\mathbf{N}$ & $\%$ & \\
\hline Tinggi & 8 & 57,1 & 6 & 42,9 & 14 & 100 & 0,05 \\
\hline Rendah & 27 & 75,0 & 9 & 25,0 & 36 & 100 & \\
\hline Jumlah & & & & & 50 & 100 & \\
\hline
\end{tabular}

Sumber: data diolah (2015)

Hasil uji statistik menunjukkan ada hubungan antara tingkat pengetahuan HIV/AIDS dengan diskriminasi tenaga kesehatan di Puskesmas Tanah Pasir terhadap ODHA. Hal ini dibuktikan dengan nilai $p$ value sebesar 0,05 .
3.2.2 Hubungan Tingkat Pengetahuan HIV/AIDS dengan Diskriminasi Tenaga Kesehatan terhadap ODHA

Hubungan tingkat pengetahuan HIV/AIDS dengan diskriminasi tenaga kesehatan terhadap ODHA ditunjukkan seperti pada tabel 3.7 berikut ini: 
Tabel 3.9 Hubungan Ketakutan yang Irasional terhadap Transmisi HIV/AIDS dengan Diskriminasi Tenaga Kesehatan terhadap ODHA

\begin{tabular}{|c|c|c|c|c|c|c|c|}
\hline \multirow{3}{*}{$\begin{array}{l}\text { Ketakutan } \\
\text { Irasional } \\
\text { terhadap }\end{array}$} & \multicolumn{4}{|c|}{ Diskriminasi } & \multirow{2}{*}{\multicolumn{2}{|c|}{ Jumlah }} & \multirow{3}{*}{ p value } \\
\hline & \multicolumn{2}{|c|}{ Tinggi } & \multicolumn{2}{|c|}{ Rendah } & & & \\
\hline & $\mathbf{F}$ & $\%$ & $F$ & $\%$ & $\mathbf{N}$ & $\%$ & \\
\hline \multirow{2}{*}{\multicolumn{8}{|c|}{$\begin{array}{l}\text { Transmisi } \\
\text { HIV/AIDS }\end{array}$}} \\
\hline & & & & & & & \\
\hline Tinggi & 20 & 86,9 & 3 & 13,1 & 23 & 100 & 0,04 \\
\hline Rendah & 12 & 55,5 & 15 & 44,5 & 27 & 100 & \\
\hline Jumlah & & & & & 50 & 100 & \\
\hline
\end{tabular}

Sumber: data diolah (2015)

Hasil uji statistik menunjukkan ada hubungan antara rasa ketakutan irasional terhadap transmisi HIV/AIDS dengan diskriminasi tenaga kesehatan di Puskesmas Tanah Pasir terhadap ODHA. Hal ini dibuktikan dengan nilai $p$ valuesebesar 0,04 yang lebih kecil dari 0,05 .

\section{Pembahasan}

\subsection{Hubungan Tingkat Pengetahuan HIV/AIDS dengan Stigma dan Diskriminasi ODHA.}

Berdasarkan hasil pengujian hubungan tingkat pengetahuan HIV/AIDS dengan stigma ODHA dengan menggunakan uji Chi Square dengan $\mathrm{a}=0,05$ diperoleh $p$-value 0,03 sehingga $p<0,05$. Sementara itu hasil pengujian hubungan tigkat pengetahuan HIV/AIDS dengan diskriminasi ODHA juga diperoleh nilai $p$-value sebesar 0,05 . Hal ini menunjukkan bahwa tingkat pengetahuan tentang HIV/AIDS mempunyai hubungan dengan stigma dan diskriminasi ODHA oleh tenaga kesehatan di Puskesmas Tanah Pasir.

Hal yang sama juga dibuktikan berdasarkan penelitian yang dilakukan pada tenaga kesehatan di Bangladesh oleh Hossain \& Kippax (2011) yang mendapatkan bahwa terdapatnya hubungan yang signifikan antara tingkat pengetahuan dengan stigma dan disriminasi terhadapat ODHA dengan hasil semakin rendahnya tingkat pengetahuan seseorang tentang penyakit HIV/AIDS maka semakin tinggi pula tingkat stigma dan diskriminasi terkait penyakit HIV/ AIDS. ${ }^{17}$

\subsection{Hubungan Ketakutan Irasional terhadap Transmisi HIV/AIDS dengan Stigma dan Diskriminasi ODHA}

Berdasarkan hasil pengujian hubungan ketakutan irasional terhadap transmisi HIV/AIDS dengan stigma tenaga kesehatan di Puskesmas Tanah Pasir terhadap ODHA dengan menggunakan uji Chi Squarediperoleh nilaip-value 0,02 sehingga $\mathrm{p}<0,05$. Sementara itu hasil pengujian $\mathrm{Chi}$ Square hubungan ketakutan irasional terhadap transmisi HIV/AIDS dengan diskriminasi tenaga kesehatan di Puskesmas Tanah Pasir terhadap ODHA diperoleh nilai $p$-value sebesar 0,04 yang lebih kecil dari $\mathrm{a}=0,05$.

Berdasarkan hasil pengujian ChiSquare tersebut, maka dapat disimpulkan bahwa ketakutan yang irasional terhadap transmisi HIV/AIDS mempunyai hubungan dengan tingkat stigma dan diskriminasi ODHA oleh tenaga kesehatan di Puskesmas Tanah Pasir. Hasil penelitian ini sesuai dengan yang diperoleh dengan hasil penelitian Hossain \& Kippax (2011) yang mendapatkan bahwa ketakutan irasional terhadap penularan HIV ditemukan menjadi salah satu prediktor sikap stigma terhadap ODHA. ${ }^{17}$ Hasil serupa juga ditemukan dalam penelitian sebelumnya yang 
dilakukan oleh Herek et al. (2002), yang menemukan bahwa ketakutan irasional menghasilkan sikap diskriminasi terhadap ODHA. Disebutkan bahwa penyebab ketakutan irasional tentang penularan HIV merupakan suatu hal yang kompleks. ${ }^{15}$

Menurut pendapat ahli psikologi Gregory M. Herek yang dikutip oleh Hossain \& Kippax (2011)mengungkapkan bahwa rasa takut terhadap penularan HIV sebagian besar hanya faktor psikologis, berdasarkan prasangka dan keyakinan yang irasional. ${ }^{17}$

\section{Kesimpulan}

Berdasarkan hasil penelitian dan pembahasan pada bab sebelumnya, maka dapat disimpulkan:

1. Tingkat stigma dan diskriminasi tenaga kesehatan di Puskesmas Tanah Pasir terhadap ODHA masih tinggi.

2. Tingkat pengetahuan tenaga kesehatan di Puskesmas Tanah Pasir tentang HIV/AIDS masih rendah.

3. Tingkat ketakutan irasional tenaga kesehatan di Puskesmas Tanah pasir tentang transmisi HIV/AIDS tinggi.

4. Tingkat pengetahuan mempunyai hubungan dengan stigma dan diskriminasi tenaga kesehatan Puskesmas Tanah Pasir terhadap ODHA.

5. Tingkat ketakutan irasional tentang transmisi HIV/AIDS mempunyai hubungan dengan stigma dan diskriminasi tenaga kesehatan Puskesmas Tanah Pasir terhadap ODHA.

\section{Saran}

1. Tenaga kesehatan di Puskesmas Tanah Pasir harus meningkatkan kapasitas pengetahuannya tentang HIV/AIDS, sehingga dengan adanya pengetahuan yang tinggi terkait HIV/AIDS akan dapat menurunkan stigma dan diskriminasi terhadap ODHA.
2. Dinas Kesehatan dapat mengadakan lebih banyak pelatihan dan seminar tentang HIV/AIDS kepada para tenaga kesehatan.

\section{Ucapan Terima Kasih}

Peneliti berterima kasih kepada fakultas kedokteran malikussaleh yang telah memfasilitasi penelitian ini, dan juga kepada para responden yang telah bersedia ikut dalam penelitian in.

\section{Daftar Pustaka}

1. Aisha Andrewin L-YC. Stigmatization of patients with hiv/aids among doctors and nurses in Belize. AIDS Patient Care and STDs 2008; 22(11).

2. Aggleton P. Comparative analysis. HIV and AIDS-related Discrimination, Stigmatization and Denial. Research studies from India and Uganda.Geneva: Joint United Nations Programme on HIV and AIDS, 2009. Available from: URL: http://data.unaids.org/publications/ir c_pub02/jc650-companal_en.pdf.

3. Bermingham S, Kippax S. HIV-related Discrimination.ASurvey of New South Wales General Practitioners: Aust N Z J Public Health 2005; 22.

4. Bharat $\mathrm{S}$ et al. India: HIV and AIDSrelated Discrimination, Stigmatization and Denial. Geneva: Joint United Nations Programme on HIV/AIDS, 2001;16-7. Available from: URL: http://data.unaids.org/publications/ir c-pub02/jc587-india_en.pdf.

5. Budiarto, Eko. Biostatistika untuk Kedokteran dan Kesehatan Masyarakat. Jakarta: EGC, 2001.

6. Brown $\mathrm{L}$ et al.Interventions to Reduce HIV/AIDS Sigma. What Have We Learned?. AIDS Educ Prev 2003;15:4969. 
7. Chandra, Budiman. Metodologi Penelitian Kesehatan. Jakarta: EGC, 2008.

8. Chen WT, Han, M., \& Holze, W.L.mer. Nurses, Attitudes and Practice Related to HIV Transmission in Northeastern China, AIDS Patient Care \& Stds, . Quoted in : Webber, GC, (2007) Chinese Health care providers attitude about HIV : a review, AIDS Care 2004;19 (5):685 - 91.

9. Collymore Y. 2002. Rooting Out AIDSrelated Stigma and Discrimination. Available

from:URL:http://www.prb.org/Article s/2002/RootingOutAIDSRelatedStigma andDiscrimination.aspx

10. Deacon \& Boulle. Comment in: Factors Affecting HIV/AIDS-related Stigma and Discrimination by Medical Professionals. Int J Epidemiol 2006; 36:185-186.

11. Depkes RI. Pedoman Penyelenggaran Sistem Surveilans Epidemologi Penyakit Menular dan Penyakit Tidak Menular. Jakarta :KepMenKes no.1479/MENKES/SK/X/2003, 2003.

12. Depkes RI. Rencana Strategi Penanggulangan HIV/AIDS Indonesia 2000-2007.Jakarta : Ditjen PPM dan PL, 2004.

13. Depkes RI. Gambaran Situasi HIV/AIDS Tahun 1987-2011. Jakarta :Pusat Data dan Informasi Departemen Kesehatan RI. 2012, 2005.

14. Dinas Kesehatan Kota Lhokseumawe. sebaran kasus HIV/AIDS di Kota Lhokseumawe 2006-2011. Lhokseumawe :Badan statistik dan seksi penanggulangan penyakit menular, 2012.

15. Herek GM et al. HIV-related Stigma and Knowledge in The United States.Prevalence and Trends, 19911999 :Am J Public Health 2002; 92:371-7.

16. Hossain MB, Kippax S. HIV-related Discriminatory Attitudes of Healthcare
Workers in Bangladesh : J Health Popul Nutr 2010; 28(2):199-207.

17. Hossain MB, Kippax S. Stigmatized Attitudes Toward People Living With HIV in Bangladesh. Health Care Workers' Perspectives: Asia-Pacific Journal of Public Health 2010; 3(2): 17182.

18. Joint United Nations Programme on HIV and AIDS. HIV-related stigma, discrimination and human rights violations. case studies of successful programmes. Geneva: Joint United Nations Programme on HIV and AIDS, 2005. Available from: URL: http://data.unaids.org/publications/ir c-pub06/jc999-humrightsviol_en.pdf.

19. KPA. Laporan KPA Nasional Tahun 2010, 2010. Available from: URL: http://www.aidsindonesia.or.id/lapor an-kpa-nasional-tahun-2010.html.

20. Lau JTF, Tsui HY. Discriminatory Attitudes Towards People Living With HIV/AIDS and Associated Factors. Sex Transm Infect. A Population Based Study In The Chinese General Population 2005;81:113-9.

21. Letamo G.Prevalence of, and Factors Associated with, HIV/AIDS-Related Stigma and Discrimination In Botswana : J Health Popul Nutr 2003; 21:347-57.

22. $\mathrm{Li} \mathrm{L}$ et al. Using Case Vignettes to Measure HIV-Related Stigma Among Health Professionals In China : Int J Epidemiology 2007; 36:178-84.

23. Mahendra VS, et al. Reducing Stigma and Discriminationin Hospital : Positive Findings from India. Horizons Research Summary, 2006.

24. Major B, O'Brien L. The Social Psychology of Stigma: Annu Rev Psychol 2005; 56:393-421.

25. Murray SR. 1972. Elementary Sampling Theory, Theory and Problems of Statistic : Mc. Graw Hill Book, Company, 1972. 
26. N. Varas-Díaz TBN, S. Malavé Rivera, and E. Betancourt. Religion and HIV/AIDS Stigma. Implications for Health Professionals In Puerto Rico: NIH Public Access Author Manuscript, 2011;1-18.

27. Ogden et al. Common at Its Core: HIVRelated Stigma Across Context, 2005. Available from: URL: http://www.icrw.org/publications/co mmon-its-core-hiv-related-stigmaacross-contexts.pdf.

28. Parker $\mathrm{R}$ et al. HIV/AIDS-Related Stigma and Discrimination. A Conceptual Framework and An Agenda for Action. New York: Horizon Program, Population Council, 2002. Available from: URL: http://pdf.usaid.gov/pdf_docs/Pnacq 832.pdf.

29. Parker R, Aggleton P. HIV and AIDSRelated Stigma And Discrimination. A Conceptual Framework and Implications for Action : Social Science and Medicine 2003;57, 13-24.

30. Pratikno H. Stigma dan Diskriminasi oleh Petugas Kesehatan terhadap ODHA Di Kabupaten Bengkalis, Propinsi Kepulauan Riau. Yogyakarta: Universitas Gadjah Mada; 2006.

31. Wan Yanhai ea. Discrimination against People with HIV/AIDS in China : The Equal Rights Review 2009; 4:15-25.

32. PBS \& Depkes RI. Laporan Hasil Survei Surveilans Perilaku 2002-2003 di indonesia. Jakarta : PBS \& Depkes RI, 2004.

33. Pulerwitz, J et al. Measuring and Addressing HIV/AIDS Stigma Among Truckers in Brazil. Paper presented at the XV International AIDS Conference Bankok, Thailand.Thailand : The 132nd Annual Meeting (November 6-10, 2004) of APHA, 2004.

34. Sayles J et al. The Association of Stigma with Self-Reported Access to Medical Care and Antiretroviral Therapy
Adherence in Persons Living with HIV/AIDS : J Gen Intern Med 2009; 24(10):1101-8.

35. Setiati S, Harimurti K, Govinda A.Infeksi HIV/AIDS. Buku Ajar Ilmu Penyakit Dalam. Jakarta Pusat : Interna Publishing, 2009.

36. Stutterheim SE et al. HIV-Related Stigma and Psychological Distress: The Harmful Effects of Specific Stigma Manifestations In Various Social Settings. AIDS, 2009; 23:17.

37. UNAIDS. HIV And AIDS-Related Stigmatization, Discrimination and Denial. Forms, Contexts and Determinants Research Studies from Uganda and India.India : Joint United Nations Programme on HIV/AIDS (UNAIDS), 2000. Available from: URL: http:// data.unaids.org/Publications/I RC-pub01/jc316-uganda-india_en.pdf.

38. AIDS Epidemic Update. Joint United Nations Programme on HIV/AIDS (UNAIDS) : UNAIDS/04.45E. ISBN 92 9173390 3, 2004. Available from: URL: http:// whqlibdoc.who.int/unaids/200 4/9291733903.pdf.

39. AIDS Epidemic Update. Joint United Nations Programme on HIV/AIDS (UNAIDS) : UNAIDS/05.19E. ISBN 92 9173439 X, 200. Available from: URL: http://www.unaids.org/epi/2005/doc /EPIupdate2005_pdf_en/Epi05_00_en. pdf

40. Van Griensven J et al. Trends in HIV Prevalence, Estimated HIV Incidence, and Risk Behavior Among Men Who Have Sex with Men In Bangkok, Thailand 2003-2007 : AIDS, 2010;53:234-239.

41. WHO. Towards Universal. Scaling Up Priority HIV/AIDS Interventions In The Health Sector. Progress report, June 2008. Geneva :World Health Organization, 2009. Available from: URL: 
http://www.who.int/hiv/pub/2008pr ogressreport/en/index.html.

42. WHO. Towards Universal Access. Scaling Up Priority HIV/AIDS Interventionsin The Health Sector. Progress report 2010. Geneva : WHO. 2010a. Available from: URL: http://whqlibdoc.who.int/publication s/2010/9789241500395_eng.pdf.
43. WHO. Classifying Health Workers. Geneva : 2010b. 